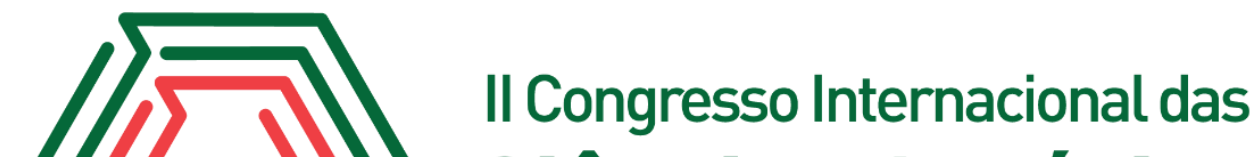 Ciências Agrárias COINTER - PDVAgro 2017
}

\section{AGRICULTURA ORGÂNICA: O USO DO BIOFERTILIZANTE LÍQUIDO AGROBIO PESAGRO-RIO}

\author{
Apresentação: Pôster \\ Eli Cristina Diniz Sousa ${ }^{1}$; Erica Ribeiro de S. Simonetti ${ }^{2}$
}

\section{Introdução}

Nos últimos anos a agricultura mundial apresenta uma preocupação com alguns efeitos resultado da tecnologia convencional não só de base agroquímica, onde o sistema orgânico de produção deve ser econômico, social e ambientalmente correto (SOUSA, 1998).

Testes realizando a partir das receitas originais do biofertilizante Super Magro deram origem ao biofertilizante Agrobio, desenvolvido pelo grupo técnico da Estação Experimental de Seropédica da PESAGRO-RIO (FERNANDES; LEITE; MOREIRA, 2006).

O biofertilizante líquido tem como papal fundamental de agenciar a autossuficiência das propriedades, com produtos mais saudáveis é de grande importância para os manejos agroecológicos. O agrobio pode ser utilizado como forma de suplementação de nutriente e como defensivo alternativo?

Objetivo geral do trabalho é enumerar os benefícios do biofertilizante agrobio, dessa forma propor o biofertilizante agrobio como fertiprotetor na agricultura orgânica, assim destacando o principal método de aplicação e recomendações de uso. A pesquisa é do tipo descritivo exploratório bibliográfico de cunho qualitativo.

\section{Fundamentação Teórica}

AGRICULTURA ORGÂNICA E DEFENSIVO ALTERNATIVO

\footnotetext{
${ }^{1}$ Técnica em agropecuária e acadêmica do curso de engenharia agronômica no Instituto Federal do Tocantins-IFTOCampus Araguatins E-mail: elicristinadinizsousa@gmail.com

${ }^{2}$ Economista, Mestre em Gestão e Desenvolvimento Regional- UNITAU, MBA em Gestão Financeira Controladoria e Auditoria (F.G.V). Professora do Instituto Federal do Tocantins-IFTO- Campus Araguatins E-mail: 
A agricultura orgânica é um sistema de produção que impede ou exclui estritamente o uso de reguladores de crescimento, agrotóxicos e aditivos para a produção vegetal alem da alimentação animal, elaborados sinteticamente (EHLERS, 1999).

Como alternativa de uma agricultura ecológica que cada vez está se tornado difícil, a manutenção sem uso de agrotóxicos, principalmente quando remete ao controle e prevenção de doenças, as estratégias que utilizam produtos biológicos conhecidos como defensivos alternativos.

De acordo com Penteado (2000), defensivos alternativos são produtos tanto de origem química, biológica como também orgânica que possuem como características das formulações, baixa ou não possuir toxicidade para a natureza e nem aos seres humanos, combater organismos microscópicos nocivos e artrópodes assim resultando em plantas resistentes.

\section{DEFENSIVOS FERTIPROTERORES}

Fernandes, Leite e Moreira (2006) fazem menção aos defensivos alternativos que são divididos em: fertiprotetores e os protetores.

Os biofertilizantes são fertiprotetores, quando oriundo de técnica de decomposição da matéria orgânica de vegetais e animais, consistido no mais popularmente gerado pelo meio da fermentação aeróbica, ou seja, com presença de oxigênio, em meio aquoso e fornecem nutrientes às plantas e as favorecem (FERNANDES; LEITE; MOREIRA, 2008)

O biofertilizante agrobio é classificado como fertiprotetores que são produtos que produz nutrientes para às plantas, favorecendo no processo metabólico das mesmas, além de contribuírem para o controle de diferentes parasitas (FERNANDES; LEITE; MOREIRA, 2006).

São destacados por Chaboussou (1995) os biofertilizantes como resultado direto no controle de artrópodes e doenças e a indução de resistência nas plantas. Em diferentes momentos o biofertilizante vem sendo utilizando sobre o solo em concentrações de até 20\%. Quando aplicado sobre o mato roçado, como "input" microbiano é capaz de adicionar a compostagem laminar (D’ANDRÉA; MEDEIROS, 2002).

\section{Metodologia}

Método utilizando na realização do trabalho foi abordagem qualitativa, nível descritivo exploratório, delineamento bibliográfica, instrumento coleta de dados em fontes secundárias. 


\section{Resultados e Discussões}

A redução do uso de agrotóxicos, tornado possível à produção em sistemas orgânicos, resultando em produtos com menos ou sem resíduo químico.

Paes (2015) cita diferentes benefícios encontrados na utilização do biofertilizante, a utilização de recursos locais (esterco animal, soro, melado) entre outros, aquisição financeira baixa, ampliação da variedade tanto de macro como micros nutrientes oferecidos para plantas, avanço da precocidade das fases do desenvolvimento da planta.

Além dos biofertilizantes possuírem odores que atuam como repelentes que atrapalham diretamente os costumes dos artrópodes e pragas ocorrem um aumento no equilíbrio de plantas com estresse (OLIVEIRA; FILHO, 2013).

Modo de preparo do biofertilizante agrobio:

Os ingredientes que serão utilizados na primeira semana, para produzir em torno de $500 \mathrm{~L}$ do Agrobio: 200 L de água, 100 L de esterco bovino fresco, 20 L de leite de vaca ou soro de leite, 3 $\mathrm{kg}$ de melaço.

Precisam ser bem misturados e deixados para fermentar por uma semana. O resultado será um caldo nutritivo, que nas sete semanas seguintes, serão acrescentados, semanalmente, os seguintes produtos antes dissolvidos em água: $1500 \mathrm{~g}$ de melaço, $850 \mathrm{~g}$ de cloreto de cálcio, $570 \mathrm{~g}$ de cinza de lenha, 430g de bórax ou ácido bórico, 143g de sulfato de magnésio, 143g de termofosfato magnesiano, $86 \mathrm{~g}$ de sulfato de manganês, $60 \mathrm{~g}$ de farinha de carne, $60 \mathrm{~g}$ de farinha de osso, $57 \mathrm{~g}$ de sulfato de zinco, $43 \mathrm{~g}$ de sulfato de cobre, $43 \mathrm{~g}$ de sulfato ferroso, $30 \mathrm{~g}$ de sulfato de cobalto, $30 \mathrm{~g}$ de molibdato de sódio, $29 \mathrm{~g}$ de torta de mamona.

Nas 4 últimas semanas, deve ser adicionado a mistura, $500 \mathrm{ml}$ de urina de vaca. A calda deve ser mexida duas vezes ao dia. Depois de 8 semanas, o volume deve ser complementado para 500 litros e posteriormente coado.

Resultado final, um produto que apresenta cor escura e odor típico de produto fermentado, com pH entre faixa de 5,0 a 6,0. Com a análise química proveu; 34,69 g/L de matéria orgânica, 0,8\% de carbono (C), 631 mg/L de nitrogênio (N) (FERNANDES; LEITE; MOREIRA, 2006).

Conforme Pinheiro e Barreto (1996), os biofertilizantes utilizados em pulverizadores, com concentrações em água de 0,1 e 5\%, e resultado dos altos teores de substâncias produzidas e altos 
efeitos hormonais.

De acordo com Santos, Monção e Ribeiro (2013) estabelecido em seu trabalho o efeito da aplicação foliar de biofertilizantes na cultura da alface crespa venerada, em altas concentrações (30 e 40\%) manifestar-se elevados no que se refere à altura das plantas nos estágios inicias de desenvolvimento das plantas de alface, entretanto, esse efeito não se sustentou ao longo do experimento desenvolvido.

O biofertilizante pode ocasionar estresse fisiológico nas plantas adiando (retardando) seu crescimento, floração ou frutificação, ocasionada pela utilização de altas concentrações do mesmo. Os resultados dos biofertilizantes para controlar doenças e insetos de plantas estão sendo comprovados pelos seus efeitos fungistático, bacteriostáticos e repelentes (MEDEIROS; LOPES, 2006).

\section{Conclusões}

Os biofertilizantes líquidos se tornam viável como alternativa na agricultura orgânica, pois barganha enumera vantagens em sua utilização, resultando em um produtor ecológico, livre de resíduos prejudiciais para saúde humana e o meio ambiente, de baixo custo, responsável por um aumento significativo na diversidade de nutrientes ofertado às plantas etc.

Em termos gerais propor o biofertilizante agrobio, pois possuir bom resultadas como fertiprotetor comprovados de acordo com o trabalho realizado, em diferentes momentos.

\section{Referências}

CHABOUSSOU, F. Plantas doentes pelo uso de agrotóxicos: a teoria da trofobiose. Porto Alegre: L\&PM, 1995. p. 256

D'ANDREA, P. A.; MEDEIROS, M. B. Biofertilizantes biodinâmicos na nutrição e proteção de hortaliças. In: CONGRESSO BRASILEIRO DE AGRICULTURA ORGÂNICA, NATURAL, ECOLÓGICA E BIODINÂMICA, 1, 2002, Piracicaba. Anais. Piracicaba: Agroecológica, 2002.

EHLERS, E. AGRICULTURA SUSTENTÁVEL: origens e perspectivas de um novo paradigma. / Eduardo Ehlers. - 2a ed. - Guaíba: Agropecuária, 1999. 157p.

FERNANDES, M. do C. de A.; LEITE, E. C. B.; MOREIRA, V. E. Defensivos alternativos: ferramenta para agricultura ecológica, não poluente, produtora de alimentos sadios. Niterói: PESAGRO-RIO, 2006, p.22.4-7(PESAGRO-RIO. Informe Técnico, 34). Disponível em: 
<http://www.pesagro.rj.gov.br/downloads/publicacao/IT34_defensivos.pdf>. Acesso em: 11 fev. 2016.

FERNANDES, M. do C. de A.; LEITE, E. C. B.; MOREIRA, V. E. Defensivos alternativos: Programa de Desenvolvimento Rural Sustentável em Microbacias Hidrográficas do Estado do Rio de Janeiro. Secretaria de Agricultura, Pecuária, Pesca e Abastecimento. (Programa Rio Rural. Manual Técnico; 1) 2008. Disponível em: <http://www.pesagro.rj.gov.br/do wnloads/rioru ral/01\% 20Defensivos\%20Alternativos.pdf >. Acesso em: 12 fev. 2016.

FERNANDES, M do c. de A.; RIBEIRO, R. de L. D.; MENEZES, e. de L. A. Manejo Ecológico de Fitoparasitas. In: AQUINO, A. M. de; ASSIS, R. L. de. Agroecologia: princípios e técnicas para uma agricultura orgânica sustentável. Brasília, DF: Embrapa, 2005, p.299.

MEDEIROS M.B. de; LOPES J. da S. Biofertilizantes líquidos e sustentabilidade agrícola, Bahia Agric., v.7, n.3, p. 24-25 nov. 2006. 3x

PAES, L. S. O. P. Biofertilizantes e defensivos naturais na agricultura orgânica, 2015 Disponível em: <http://web.ademadan.org.br/wp-content/uploads/2015/12/Cartilha-Biofertilizantese-defensivos-naturais-na-agricultura-org\%C3\%A2nica_ADEMADAN_site.pdf >. Acesso em: 11 de fev. 2016

PENTEADO, S. R. Defensivos alternativos e naturais: para uma agricultura saudável. Campinas/SP 2000. p. 37

PINHEIRO, S.; BARRETO, S. B. Agricultura sustentável, trofobiose e biofertilizantes. Porto Alegre: Junquira Candiru. 1996, p.276. Tradução de DINCHEV, D. Agroquímica. Ciudade de La Havana, Cuba: Ed. Revolucionaria, 1996, p. 295.

OLIVEIRA, P. C. de; FILHO, C. Cartilha de receitas alternativas para prevenção e controle de pragas e doenças na agricultura, ca. 2013 Urucurituba e Tapará Grande /PA. Disponível em: < http://otca.info/gef/uploads/documento/6b09f-CARTILHA-40.pdf >. Acesso em 11 fev 2016.

SANTOS, A. de J.; MONÇÃO O. P.; RIBEIRO P. R. C. de C. et al. Efeito da aplicação foliar de biofertilizante na cultura da Alface crespa veneranda (lactuca sativa 1. .) Enciclopédia biosfera, centro científico conhecer - Goiânia, v.9, n.17; p.1140 - 1149, 2013.

SAYÃO, C. R. D. O biofertilizante Agrobio: composição microbiológica e seus efeitos no controle da mancha bacteriana em mudas de pimentão (Capsicum annuum). 2001. 49 p. Dissertação (Mestrado em Fitotecnia) -Universidade Federal Rural do Rio de Janeiro, Seropédica, RJ 2001.

SOUSA, J. L. de. Agricultura Orgânica: Tecnologia para a produção de alimentos saudáveis.Vitória ES: EMCAPA, 1998. 